\title{
Seismicity in Sales Oliveira (SP)
}

\author{
A. F. Hincapie-F., Jaime Convers, Marcelo Assumpçao, Universidade de São Paulo
}

Copyright 2021, SBGf - Sociedade Brasileira de Geofísica.

This paper was prepared for presentation during the $17^{\text {th }}$ International Congress of the Brazilian Geophysical Society held in Rio de Janeiro, Brazil, $16-19$ August 2021.

Contents of this paper were reviewed by the Technical Committee of the $17^{\text {th }}$ International Congress of the Brazilian Geophysical Society and do not necessarily represent any position of the SBGf, its officers or members. Electronic reproduction or storage of any part of this paper for commercial purposes without the written consent of the Brazilian Geophysical Society is prohibited.

\begin{abstract}
Small tremors began to be felt in Sales Oliveira, a city in the northeast of the state of São Paulo. The date they were first reported was August 13, 2019. A small network was installed in the municipality to monitor this activity. These events began to be felt a week after the opening of a deep well in the city, which could be the cause of the tremors. The objective is to establish the causes of these tremors and whether or not they are related to the opening of deep wells.

Several authors have studied the possible mechanisms of induced seismicity, such as changes in pore pressure, and structural or lithological changes that can alter accumulated stresses and generate tremors. One of the most studied processes is the injection or extraction of water through deep wells.

Historically, in Brazil, several cases of seismicity induced by the opening of wells to extract water have been reported. Initially, cases of seismic activity were reported in the municipality of Fernando Prestes in the 1950s. In 1977, tremors were recorded in the municipality of Nuporanga. The reported tremors began to be felt in the month of May, when the opening of a well was completed. A second period of seismicity was felt in December, after the opening of a second well. The events reported reached an intensity of IV on the modified Mercalli scale.

In this work, 55 events registered by the seismographic network installed in Sales Oliveira between August 2019 until May 2021 have been located, the highest recorded magnitude is $2.1 \mathrm{Mb}$ and the maximum depth of the hypocenters does not exceed $2 \mathrm{~km}$ of depth. The vast majority of registered epicenters cover in area a not very extensive region of maximum $4 \mathrm{~km}^{2}$.

For an initial location, the hypo71 algorithm was used with an initial velocity model based on the characteristics of the soil reported by the municipal water extraction wells. A two-layer model was used, the average thickness of the soil layer was estimated at $30 \mathrm{~m}$, the second layer was considered basalt according to the information obtained. For a second location and in order to improve the model, the VELEST algorithm was used to minimize the RMS by varying both the location and the model, tests were made by varying the depth and the initial velocity in the algorithm. In this way, the RMS was reduced to 0.02 seconds.

In addition, a chain of events that occurred in the month of January 2020 was studied, which could establish a high correlation between the registered waveform, indicating that they could be produced in the same source, thus, the HypoDD algorithm was used in order to find a relative location of the events.

On the other hand, an attempt was made to estimate if the epicenters were moving away from a possible initial source as expected in pore pressure diffusion processes, in the initial months this could be observed, but according to the events of 2020 it is not possible to conclude this . It is possible that the water injection and extraction process has only reactivated old faults located in the municipality.
\end{abstract}

